\title{
Allergic reactions following contrast material administration: nomenclature, classification, and mechanisms
}

\author{
Cristian Palmiere • Lionel Comment • Patrice Mangin
}

Received: 30 July 2013 / Accepted: 3 September 2013 /Published online: 24 September 2013

(C) Springer-Verlag Berlin Heidelberg 2013

\begin{abstract}
In forensic pathology routine, fatal cases of contrast agent exposure can be occasionally encountered. In such situations, beyond the difficulties inherent in establishing the cause of death due to nonspecific or absent autopsy and histology findings as well as limited laboratory investigations, pathologists may face other problems in formulating exhaustive, complete reports, and conclusions that are scientifically accurate. Indeed, terminology concerning adverse drug reactions and allergy nomenclature is confusing. Some terms, still utilized in forensic and radiological reports, are outdated and should be avoided. Additionally, not all forensic pathologists master contrast material classification and pathogenesis of contrast agent reactions. We present a review of the literature covering allergic reactions to contrast material exposure in order to update used terminology, explain the pathophysiology, and list currently available laboratory investigations for diagnosis in the forensic setting.
\end{abstract}

Keywords Allergic reactions - Adverse drug reactions . Contrast material $\cdot$ Mast cells $\cdot$ Anaphylaxis $\cdot \beta$-tryptase

\section{Introduction}

Adverse drug reactions are relatively frequent in clinical practice and can be responsible for serious health problems. The most common are correlated to a known pharmacologic or toxic drug property, are predictable and may occur in anyone. Less common adverse reactions, which include allergy, do not depend on the pharmacologic property of the drug and may occur in people with a certain predisposition. These reactions are therefore unpredictable [1,2].

C. Palmiere $(\bowtie) \cdot$ L. Comment $\cdot$ P. Mangin

University Centre of Legal Medicine, Rue du Bugnon 21,

1011 Lausanne, Switzerland

e-mail: cristian.palmiere@chuv.ch
Several drugs have been implicated as causing adverse reactions, some potentially life-threatening. Reactions to radiocontrast media, magnetic resonance imaging (MRI) contrast agents, and contrast material used in neurosurgery as well as ophthalmic surgery represent a portion of adverse drug reactions.

In the medicolegal setting, fatal cases of contrast agent exposure can be occasionally encountered. In these situations, beyond the classical problems inherent in establishing the cause of death that are related to nonspecific or absent macroscopic and microscopic findings as well as limited, reliable laboratory investigation tools, forensic pathologists may face difficulties in formulating exhaustive reports and conclusions.

Indeed, numerous fatal and nonfatal cases of adverse reactions to contrast material exposure have been described in radiological and medicolegal literature. However, the terms that appear in different reports are often used interchangeably though they should not be. Though still utilized in some circumstances, some terms (pseudoallergic, anaphylactoid, etc.) are outdated and should be avoided. In addition, not all forensic pathologists are at ease with contrast agent terminology. This makes the elaboration of reports on autopsy even more challenging since they must be understandable for the inquiring authorities, precise regarding used terminology, and scientifically unobjectionable at the same time.

The aim of this article was to examine the radiological and medicolegal literature pertaining to adverse reactions to contrast material exposure in order to shed light on classification, pathophysiology, and postmortem diagnosis of reactions to contrast material.

\section{Adverse drug reaction and allergy nomenclature}

Adverse drug reactions are broadly categorized into predictable and unpredictable. Predictable reactions are usually dosedependent, are related to the known pharmacologic actions of the drug, and occur in otherwise healthy individuals. They are 
subdivided into overdoses, side effects, secondary effects, and drug interactions. Unpredictable reactions are generally dose independent, are unrelated to the pharmacologic actions of the molecule, and occur in susceptible subjects only. They are subdivided into drug intolerance, drug idiosyncrasy, and drug allergy or immunologic reactions. Unpredictable reactions also include pseudoallergic reactions, also called anaphylactoid reactions, which are due to the direct release of mediators from mast cells and basophils. However, the World Allergy Organization has proposed that reactions without an immunologic mechanism be referred as nonallergic reactions and that the terms pseudoallergic and anaphylactoid no longer be used [1-6].

A consensus statement from the World Allergy Organization clarified the classification of allergic and nonallergic drug reactions based on the mechanism initiating the inflammatory reaction causing symptoms and signs.

According to the revised nomenclature, the term hypersensitivity should be used to describe objectively reproducible symptoms or signs initiated by exposure to a defined stimulus at a dose tolerated by normal persons.

Allergy is a hypersensitivity reaction initiated by specific immunologic mechanisms. When other mechanisms can be proven, the term nonallergic hypersensitivity should be used.

Allergy can be antibody-mediated or cell-mediated. In most patients with allergic symptoms from mucosal membranes in the airways and gastrointestinal tract, the antibodies belong to the $\operatorname{IgE}$ isotype and these patients may be said to have an IgE-mediated allergy. $\operatorname{IgE}$ in this context refers to $\operatorname{IgE}$ antibodies to an allergen. An allergen is an antigen causing allergic disease.

In non-IgE-mediated allergy, the inflammation involves allergen-specific lymphocytes, as in allergic contact dermatitis or antibodies of the $\operatorname{Ig} G$ isotype.

On the basis of these definitions, the appropriate term for food hypersensitivity is food allergy when immunologic mechanisms have been demonstrated. Food-specific IgG antibodies in serum are not of clinical importance but merely indicate previous exposure to the food. If $\mathrm{IgE}$ is involved in the reaction, the term IgE-mediated food allergy is appropriate. Other reactions should be referred to as nonallergic food hypersensitivity.

Likewise, when immunologic mechanisms, either antibody or cell-mediated, have been demonstrated, reactions should be referred to as drug allergy. Adding the adjectives immediate or delayed, both describes the onset of symptoms and indicates the probable immunological mechanism involved, i.e., IgE or lymphocyte cell-mediated, respectively. IgE-mediated drug allergy represents a smaller fraction of drug hypersensitivity.

Lastly, insect venom and saliva hypersensitivity mediated by an immunologic mechanism should be referred to as venom or saliva allergy, as in bee venom allergy.
The term anaphylaxis is used differently by physicians throughout the world. It has been proposed that anaphylaxis is the umbrella term for an acute reaction defined as follows: anaphylaxis is a severe, life-threatening generalized or systemic hypersensitivity reaction. The term allergic anaphylaxis should be used when the reaction is mediated by an immunologic mechanism, e.g., IgE or immune complexes. An anaphylactic reaction mediated by IgE antibodies, such as peanutinduced food anaphylaxis, may be referred to as $I g E$-mediated allergic anaphylaxis. Conversely, anaphylaxis from any nonimmunologic cause should be referred to as nonallergic anaphylaxis $[2,7,8]$.

\section{Immune response mechanisms}

Drug allergies are mediated by the immune system. However, it is often difficult to differentiate between immune- and nonimmune-mediated adverse drug reactions. Since the clinical signs and symptoms of most immune reactions are observed only in the elicitation phase and not in the preceding sensitization phase, the dogma has been that allergy to drugs are only observed on re-exposure or longer-lasting exposure to the drug. However, more recent data has shown that previous contact with the causative drug is not a prerequisite for immune-mediated drug hypersensitivity. These findings indicate that the paradigm must be changed, and that drug allergies might be best explained by cross-reactivity between the drug involved and other molecules to which the affected subject may have been previously exposed.

The sensitization phase primarily involves stimulation and expansion of drug-specific lymphocytes. This may affect $\mathrm{T}$ cells alone or both $\mathrm{T}$ cells and $\mathrm{B}$ cells, with consequent formation of drug-specific antibodies (mostly IgE).

Drug molecules and their metabolites are too small to elicit an immune response by themselves. Thus, to be immunogenic, they are thought to act as haptens or prohaptens. Haptens are chemically reactive, small molecules that covalently bind to a larger protein or peptide. Prohaptens are inert drugs that undergo metabolism (bioactivation) and become reactive metabolites (haptens), which can then bind covalently to a protein that acts as a carrier.

In addition to drug- and drug metabolite-carrier complexes, drug-independent cross-reactive antigens can also induce sensitization. This phenomenon of immunologic cross-reactivity occurs when an immune response to one antigen results in reactivity to structurally related antigens. Cross-reactivity mediated by immunologic mechanisms is usually explained by the presence of a common antigenic determinant in crossreacting drugs. Cross-reactivity can also derive from nonspecific binding of drugs to IgE on the surface of mast cells and basophils. Most cross-reactivity syndromes are thought to be due to $\mathrm{IgE}$ antibodies. However, there is also 
support for T cell-mediated cross-reactivity, independent of IgE-mediated mechanisms [1, 9-11].

After primary sensitization to a causative drug, renewed contact with the antigen may induce the elicitation phase, corresponding to type I to IV immune reactions (Gell and Coombs classification). Most commonly observed drug allergies are type I or IV reactions, whereas type II and III are encountered infrequently.

Type I reactions are based on IgE-mediated hypersensitivity. The soluble IgE produced by B cells circulates and binds to the receptor located on the surface of mast cells and basophils. Mast cells are tissue-resident cells that can be found in the skin, gut, and respiratory tract as well as adjacent to nerves and blood vessels. Among their most important immune functions is the propensity to bind circulating $\operatorname{IgE}$ utilizing the high-affinity IgE receptor. When an allergen is re-encountered and recognized by IgE antibodies bound to mast cell surface, the activated mast cell undergoes degranulation. The immediate liberation of preformed mediators such as histamine, tryptase, chymase, carboxypeptidase, cathepsin G, and heparin elicits the acute symptoms of type I hypersensitivity reactions in the skin, gut, respiratory, and cardiovascular systems. These symptoms typically begin within minutes of antigen exposure. Serum tryptase is not uniformly elevated in food allergy, leading some to question whether basophils play a larger role than mast cells do in human food allergy. Mast cells also synthesize other mediators such as leukotrienes and prostaglandins upon activation, requiring several hours to achieve their inflammatory effects, including recruitment and activation of secondary immune cells such as eosinophils.

Delayed hypersensitivity type IV reactions are mediated by cellular immune mechanisms and may have a variety of clinical manifestations ranging from skin involvement alone to fulminant systemic diseases. A recently proposed modification subdivides type IV reactions into four categories involving activation and recruitment of monocytes (IVa), eosinophils (IVb), $\mathrm{CD}^{+}$or $\mathrm{CD}^{+} \mathrm{T}$ cells (IVc), and neutrophils (IVd). The classic reaction in hypersensitivity type IV is contact dermatitis $[1,4,9,12-16]$.

\section{Contrast medium classification and mechanism of adverse reactions}

Iodinated radiocontrast media are among the most commonly used contrast agents in radiology. They are subdivided into ionic monomer, ionic dimmer, nonionic monomer, and nonionic dimmer.

Additionally, iodinated contrast agents can be classified by their osmolality relative to blood and are typically described as high, low, and iso-osmolar.

Modern radiocontrast agents can be used almost everywhere in the body. Most often they are used intravenously though they can be administered intra-arterially, intrathecally, and intra-abdominally.

Iodine is the element used in radiocontrast media as it possesses important properties essential for the production of contrast, including high-contrast density and low toxicity.

Contrast agents are also used in MRI though these are not made of iodine. Currently, available MRI contrast agents can be classified in various ways according to their various features, such as the presence and nature of their metal center and their magnetic properties (paramagnetic or superparamagnetic agents). Regarding the metal center, the simplest one is a single paramagnetic ion bound to an organic ligand in a chelate. The paramagnetic ion is usually gadolinium $\left(\mathrm{Gd}^{3+}\right)$ or manganese $\left(\mathrm{Mn}^{2+}\right)$, and the most common ligands are linear or macrocyclic polyaminocarboxylate/phosphonate derivatives. Most contrast-enhanced MRI procedures worldwide are performed with MRI contrast agents based on chelates of the paramagnetic ion gadolinium [17-20].

Although their frequency is low, adverse reactions to contrast agents in general, and allergic reactions in particular, are responsible for relevant morbidity and may quickly become life-threatening. Iodinated contrast media, gadolinium-based contrast agents, microbubbles used as ultrasound contrast agents and contrast material used in ophthalmic surgery are all able to induce adverse reactions that can either be allergic or nonallergic and may be either immediate or delayed [21].

Katayama et al. [22] found that $70 \%$ of adverse reactions to iodinated contrast media occurred within the first $5 \mathrm{~min}$ following contrast material injection. Whereas immediate reactions occur within $1 \mathrm{~h}$ of administration, delayed adverse reactions are defined as reactions occurring from $1 \mathrm{~h}$ up to 10 days after contrast material administration. Skin reactions including maculopapular rashes, erythema, swelling, and pruritus are common and account for most delayed hypersensitivity reactions. Most skin reactions are mild or moderate, self-limiting, and involve $\mathrm{T}$ cell-mediated mechanisms. Acute life-threatening or fatal reactions to iodinated contrast media may occur following intravenous or intra-arterial injection but may also develop after alimentary or intracavitary administration due to the absorption of iodinated contrast material particles into circulation [23].

The mechanisms of immediate reactions to iodinated contrast media are still a matter of speculation. There is some indirect evidence that they may be caused by an IgE-mediated mechanism. Indeed, immediate reactions to radiocontrast media are associated with histamine and other mediator release from basophils and mast cells. Additionally, it has been demonstrated that patients with hypersensitivity reactions after radiocontrast agent exposure had increased plasma levels of both histamine and tryptase. Furthermore, the levels of both molecules correlated with the severity of the reaction.

However, nonimmunologic mechanisms have also been postulated. Symptoms of nonallergic reactions to radiocontrast material are caused by histamine release from 
mast cells and basophils either directly by a membrane effect possibly related to the osmolality of the contrast material solution or the nonspecific binding of contrast material molecules on membrane $\operatorname{IgE}$ or indirectly by an activation of the complement system and a bradykinin-induced mechanism. In vitro and in vivo evidence is provided, indicating that both ionic and nonionic contrast media activate plasma kallikrein with consecutive factor XII contact phase activation as well as stimulation of the bradykinin generation. Furthermore, activation of the complement cascade via classic and alternative pathways was described to some extent for intravascular application of contrast agents. In nonreactors, these alterations are transient and have only a limited extent, indicating that these reactions are within the regulatory capacity of the kallikrein-kinin-factor XII system. In reactors, however, significant evidence for extended kallikrein system activation is associated with reduced $\mathrm{C} 1$-esterase inhibitor levels. Therefore, individuals with alterations in these systems could be regarded as candidates for nonimmunologic, adverse reactions to contrast agents [24-27].

An important argument against the immunologic mechanism is that patients can react to contrast media on first exposure and that reactions do not always occur. It has been proposed that previously non-exposed patients might have already been sensitized, though the molecules responsible for the sensitization remain unknown. Various factors favor a nonallergic mechanism in these cases. These factors include that contrast media are small-sized molecules thereby necessitating haptenization to become immunogenic, that patients can react on initial exposure, that contrast material-specific IgE antibodies are not systematically detected in patient serum, and that positive skin tests can be found in only a minority of subjects. Furthermore, the affinity of $\operatorname{IgE}$ to a contrast agent is extremely low and suggests a nonspecific rather than specific binding, the latter occurring only at high concentrations of the compound [11].

On the other hand, however, the positive skin tests in some individuals as well as the detection of contrast materialspecific IgE antibodies reported by some investigators in a fraction of patients support the concept that the IgE-mediated mechanism may be one of the possible mechanisms, at least in a portion of these patients. More recent research has described positive skin tests with cross-reactivity to similar radiocontrast material in patients who reported a radiocontrast material allergy. T cell cross-reactivity between various radiocontrast agents has also been described in some patients with delayed hypersensitivity reactions [2, 11, 28, 29].

Immediate reactions have been reported in association with intravenous administration of gadolinium-based contrast agents. The pathophysiologic mechanisms, however, are not completely understood. Based on positive skin tests to the contrast material that caused the reaction, some reports suggested an IgE-mediated mechanism. However, it is still unclear whether polysensitization and cross-reaction exist within similar molecules. Another report suggesting an immunologic mechanism showed that the risk of immediate hypersensitivity reactions to gadolinium-based contrast media was up to eight times higher in patients who had had previous reactions to gadolinium-based contrast agents, with the second reaction tending to be more pronounced than the first [30, 31]. However, Kun and Jakubowski [20] demonstrated that ionic and nonionic preparations of MRI contrast agents were able to directly induce mast cell degranulation in vitro, suggesting that the mechanism (or one of the mechanisms) responsible for mast cell degranulation belong to the group of IgEindependent reactions.

Sodium fluorescein and 5-aminolevulinc acid are the most common fluorescent dyes used in brain tumor surgery. The exact pathogenesis of adverse reactions to fluorescein is still unknown and may be multiple. An immunologic, IgE-mediated mechanism has been proposed to explain fluorescein-induced hypersensitivity reactions in both ophthalmic and neurosurgery cases. However, an argument against the allergic nature of the reaction is that patients can react to fluorescein on first exposure. In these cases, the chemical structures and route responsible for the sensitization are unknown. An allergy history of drug and/or food has been identified as one of the major risk factors for adverse reaction during fluorescein angiography. However, nonimmunologic reactions are now believed to be the main type of reaction found with intravenous, oral, and even topical fluorescein. A marked reduction in reactions was reported after oral fluorescein administration, though adverse reactions can still occur [32].

Severe reactions following indocyanine green injection for angiography were described in ophthalmic literature and two deaths were reported with nonophthalmic use of indocyanine green. Though both terms, "anaphylactic" and "anaphylactoid," are mentioned in these reports, an immunologic mechanism was not proven and dependency on the applied dose was also postulated [33-40].

IgE-mediated and non-IgE-mediated immunologic reactions were described in association with patent blue $\mathrm{V}$ administration used in the identification of sentinel lymph nodes during staging procedures in patients with breast cancer and other malignancies. Allergic reactions during sentinel lymph node biopsy in breast cancer have also been reported with isosulfan blue. Adverse reactions related to echocardiographic contrast agent use (intravenous succinylated gelatin (Gelofusine) during transthoracic echo bubble study, intravenous perfluoropropane gas in lipid microbubbles (Perflutren) during contrast echocardiography, and intravenous sulphur hexafluoride (Sonovue) during contrast echocardiography) are mentioned in the literature as "severe anaphylaxis," "hemodynamic instability," and "anaphylactic shock," respectively. Adverse reactions to succinylated gelatin and other plasma expanders are well described. Pathogenesis is unclear, and both $\operatorname{IgE}$ and non-IgE mechanisms have been proposed. 
Conversely, an immunologic mechanism explaining an adverse reaction to perfluoropropane and sulphur hexafluoride was not demonstrated [41-48].

\section{Markers of mast cell activation}

Mast cells are the primary effector cells of immediate hypersensitivity reactions. Activated mast cells release both preformed and newly synthesized mediators. The former include histamine, heparin, and several proteases such as tryptase, chymase, mast cell carboxypeptidase, and cathepsin G. The latter include lipid mediators such as prostaglandin $\mathrm{D}(2)$ and leukotriene $\mathrm{C}(4)$ as well as cytokines and interleukins.

$\beta$-tryptase is the main protease in all mast cells, although basophils also contain trace amounts. Currently, only mast cells and basophils have been shown to express tryptase mRNA.

Many of these mediator are stored in cytoplasmic granules, and their release may be induced by (a) chemical substances (toxins and venoms), (b) physical factors (mechanical trauma and high or low temperatures), (c) endogenous mediators (tissue protease and cationic proteins derived from eosinophils and neutrophils), and (d) immune mechanisms that can be IgE-dependent or IgE-independent.

IgE-dependent release is caused when allergens bind $\operatorname{IgE}$ antibodies expressed by both mast cells and basophils.

Although mast cells reside in tissue and basophils typically in blood, histamine can be released from either cell type. Conversely, since negligible amounts of tryptase are present in basophils, increased blood tryptase levels selectively indicate mast cell activation. Blood tryptase levels generally correlate with the clinical severity of the reaction. However, the route of allergen exposure appears to be able to influence tryptase levels, possibly related to the subtype of mast cell the allergen first encounters. Mast cells that predominate in the lungs and intestinal mucosa contain much less tryptase per cell than those in connective tissues. Thus, tryptase levels may correlate poorly in food anaphylaxis for example.

Physical factors such as high and low temperatures and some drugs, for instance opioids, are thought to be able to directly determine mast cell and basophil degranulation with a mechanism independent from immune system involvement. It must be emphasized, however, that diverging conclusions exist on this issue in the literature. Whereas some studies have demonstrated that rapid vancomycin infusion was accompanied by a significant increase in plasma histamine without an increase in plasma tryptase values, other investigations concluded that tryptase is released with histamine during nonimmunologic mast cell activation.

Mediators other than histamine and tryptase can be considered as clinical markers of mast cell activation. Leukotriene $\mathrm{C}(4)$ and prostaglandin $\mathrm{D}(2)$ are both secreted by activated mast cells. Although basophils do not produce prostaglandin
$\mathrm{D}(2)$, platelets, Langerhans cells and other antigen-presenting cells contain prostaglandin $\mathrm{D}(2)$ synthase, and are able to generate prostaglandin $\mathrm{D}(2)$. Thus, the source of prostaglandin $\mathrm{D}(2)$ measured in blood may be uncertain. Likewise, leukotrienes are not uniquely produced by mast cells and their determination in blood would therefore not distinguish mast cell involvement from other inflammatory cells such as eosinophils and basophils. Proteoglycans inside mast cells have also been suggested as possible indicators of mast cell activation. While heparin is uniquely stored and released from mast cells, currently, there is no practical assay of sufficient specificity and sensibility. Cathepsin $G$ is also present in human neutrophils. Mast cell carboxypeptidase and chymase are potential markers for mast cell involvement, but thus far no assays of adequate sensitivity and specificity for use with biologic specimens have been developed [49-51].

\section{Diagnosis of fatal reactions to contrast agents in the forensic setting}

Anaphylaxis is an acute, life-threatening systemic reaction with varied mechanisms, clinical presentations, and severity that results from the sudden, systemic release of mediators from mast cells and basophils. Diagnosis is based on suggestive clinical symptoms after exposure to potential triggering agents or events. Clinical diagnoses may be supported by laboratory investigations. Currently, histamine and $\beta$-tryptase are the classic laboratory parameters available for routine analyses.

Increased serum $\beta$-tryptase levels often correlate with increased histamine concentrations, though imperfect interrelations may be observed since $\beta$-tryptase diffuses through tissues more slowly than histamine, presumably because of its association with the macromolecular protease/proteoglycan complex. During insect sting-induced anaphylactic hypotension, $\beta$ tryptase levels are at their max 15 to 120 min after the sting, whereas histamine peaks at approximately 5-10 min after symptom onset and decline to the baseline within $60 \mathrm{~min}$ as a result of rapid metabolism by $N$-methyltransferase and diamine oxydase. Peak $\beta$-tryptase levels decline with a half-life of 1.5 to $2.5 \mathrm{~h}$, and $\beta$-tryptase levels may remain elevated for up to $5 \mathrm{~h}$.

The practical consequence of the differing kinetics of histamine and $\beta$-tryptase appearance and elimination from blood is that samples for histamine determination must be obtained within 15 min of episode onset, which might only be possible in a small proportion of reactions, precluded in most circumstances when reactions occur outside the hospital. Conversely, blood samples for $\beta$-tryptase measurement can be obtained up to several hours after the reaction begins, depending on its severity.

Although elevated serum $\beta$-tryptase concentrations support the existence of mast cell activation and hypersensitivity reactions, failure to document its elevation does not refute this diagnosis. Indeed, $\beta$-tryptase has been found to be within the 
normal range in asthmatic deaths. In addition, some cases of clinically diagnosed hypersensitivity reactions to orally ingested food allergens fail to show elevated $\beta$-tryptase levels, though abundant amounts of IgE against the ingested allergen can be detected. These findings would suggest that food allergies might not be dependent on mast cell activation and result in more basophil than mast cell activation [49, 51, 52].

Furthermore, besides cases of hypersensitivity reactions, elevated $\beta$-tryptase levels have been identified in both serum and postmortem serum in salicylate overdose, crushing blunt force trauma, coronary artery atherosclerosis with and without myocardial infarction, drug-related (mostly heroin) deaths, and sudden infant death syndrome. Indeed, mast cells, histamine, and $\beta$-tryptase are currently thought to be involved in the cascade of events potentially linking eroded or ruptured coronary plaques, coronary spasms, acute thrombotic occlusions, and myocardial infarction [52-58].

The identification of fatal anaphylaxis may be extremely challenging in forensic pathology routine. Acute hypersensitivity reactions are uncommon though well-recognized causes of sudden death. Diagnosis during postmortem examination may not be considered unless it was previously suspected based on anamnesis, circumstances, or available medical information. Factors that suggest allergic hypersensitivity reactions include an immediately preceding challenge with an allergen known to cause reactions, clinical features consistent with or suggesting hypersensitivity reactions, a previous history of reactions to similar or cross-reactive allergens, specific IgE antibodies to the allergen thought to have caused the reaction, as well as measurable products of mast cell activation and degranulation.

Unfortunately, most forensic cases have incomplete, unreliable, or absent medical records when bodies are admitted to the mortuary for medicolegal investigations. Additionally, macroscopic and microscopic findings may be absent, leading to the conclusion that the diagnosis of fatal anaphylaxis in the forensic setting often relies exclusively on circumstantial evidence when available and the exclusion of other potential causes of death after all postmortem investigations.

Autopsy should be carried out as soon as possible when death from acute hypersensitivity reactions is suspected.

Due to its short half-life of minutes, histamine can only be detected in blood for a short period of time. Furthermore, histamine is not stored exclusively in mast cells but also in basophils. For this reason, histamine measured in postmortem serum is most likely released from basophils during hemolysis.

Histamine is partly metabolized to $N$-methyl-histamine and excreted in urine. Urinary measurement of $N$-methyl-histamine may be useful in living subjects after hypersensitivity reactions since it is detectable up to $24 \mathrm{~h}$ after an episode, with a significant peak within the first $3 \mathrm{~h}$. However, genitourinary bacteria may be capable of converting histidine to histamine and falsely elevating urinary levels of histamine and its metabolites. Hence, urine $N$-methyl-histamine measurements are not reliable after death, while urinary samples obtained immediately prior to death or immediately postmortem could be useful for laboratory assays.

Markedly increased concentrations of $\beta$-tryptase in postmortem serum have been reported by several authors who examined cases of sudden death in individuals who may have died in the course of hypersensitivity reactions. According to some observations, $\beta$-tryptase levels can be assessed in postmortem serum even days after death. Nevertheless, other authors evaluate postmortem serum $\beta$-tryptase concentrations carefully and claim that results on $\beta$-tryptase levels in postmortem samples may not be relied upon to the same degree as in clinical examination mainly because of decompositional changes. Moreover, as stated above, increased levels of postmortem serum $\beta$-tryptase can be frequently observed in subjects with causes of death unrelated to hypersensitivity reactions. In addition, due to decompositional changes involving organs, tissues, and biological fluids, the main laboratory procedures currently applied on samples obtained from living individuals after hypersensitivity reactions are not necessarily or extensively applicable to samples collected during autopsy. Indeed, the concentration and stability of many analytes may be modified under the effects of different thanatological processes that may cause cytolysis and chemical molecule degradation even immediately after death. Biochemical or immunological assays are therefore not necessarily reliable when performed on samples obtained postmortem.

This leads to the conclusion that postmortem straightforward diagnoses of fatal hypersensitivity reactions cannot be exclusively based on $\beta$-tryptase determination alone.

Total and specific IgE may be measured in postmortem serum. Even at average room temperature, the total amount of $\mathrm{IgE}$ is considered relatively stable after death. However, high titers of total IgE only provide information on atopic disposition whereas high titers of allergen-specific $\operatorname{IgE}$ indicate the degree of sensitization to a particular allergen and confirm that an IgE-mediated event has occurred, thereby not proving death preceded by acute hypersensitivity reactions. Total $\operatorname{IgE}$ may be elevated in many atopic individuals. Additionally, some people with atopy may not display any detectable IgE elevation, as some allergens may not proceed through an IgE pathway to activate a response. Thus, relatively high titers of IgE, specific for a given allergen, may not cause generalized IgE elevations beyond clinical reference ranges. Moreover, similar to $\beta$-tryptase, elevation of total IgE has been reported in association with trauma and other conditions with a significant inflammatory component. Furthermore, total IgE levels tend to rise with prolonged survival. Lastly, total IgE may be elevated in other nonatopic conditions, including parasitic and fungal infections. If the identity of the allergen causing fatal hypersensitivity reaction is known or suspected, a specific $\operatorname{IgE}$ assay for the allergen may be pursued to assess reactivity, ostensibly providing a more specific means of diagnosing fatal 
anaphylaxis. Hence, an increase in $\operatorname{IgE}$ alone cannot prove death by acute hypersensitivity reactions.

Finally, the forensic use of postmortem serum chymase levels has been tested, at present, exclusively in one study. This found a significant, positive correlation between tryptase and chymase levels, thus suggesting that measurements of mast cell-specific chymase levels could be an additional tool for the postmortem diagnosis of hypersensitivity reactions characterized by mast cell activation [59-66].

Laboratory investigations that can be performed in cases of fatal adverse reactions to contrast material are summarized in Table 1.

\section{Conclusions}

Adverse reactions to drugs and contrast material are relatively frequent in clinical practice. The most common are predictable and dose-dependent. True allergies to contrast material constitute a minority of these, with fatal cases being extremely rare. With increased utilization of specialized investigations with contrast medium administration, the likelihood of encountering subjects who experience life-threatening, adverse reactions has also significantly increased over the years. Though fatal cases do not necessarily imply medical malpractice, physicians and radiologists may be involved in cases of medical negligence with medicolegal autopsies requested by the inquiring authorities. Therefore, forensic pathologists must, at all times, be aware of the possible effects related to contrast material utilization, underlying pathophysiological mechanisms and diagnostic tools. As stated above, fatal cases following contrast material administration are rare. Unfortunately, some laboratory analyses are not readily available in all the facilities where postmortem examinations are performed. Additionally, some analyses are not integrated in routine autopsy investigations in most medicolegal centers. Further collaborations involving laboratories and medicolegal centers worldwide would thereby allow data pertaining to fatal cases to be collected and centralized with the aim of exchanging information internationally and improving the diagnostic potential in the forensic field.

Not only iodinated contrast media but also gadoliniumbased contrast agents, ultrasound contrast material, and contrast media used in ophthalmic surgery are able to induce lifethreatening and potentially fatal adverse reactions. These can be initiated by specific immunologic or nonimmunologic mechanisms and may be either immediate or delayed. An IgE-mediated, allergic mechanism may be one of the possible mechanisms responsible for immediate reactions to radiocontrast agents, at least in a portion of patients, though several clinical observations favor a nonallergic mechanism in some of these cases. Likewise, the role of IgE in MRI contrast material reactions has been suggested in a portion of patients,

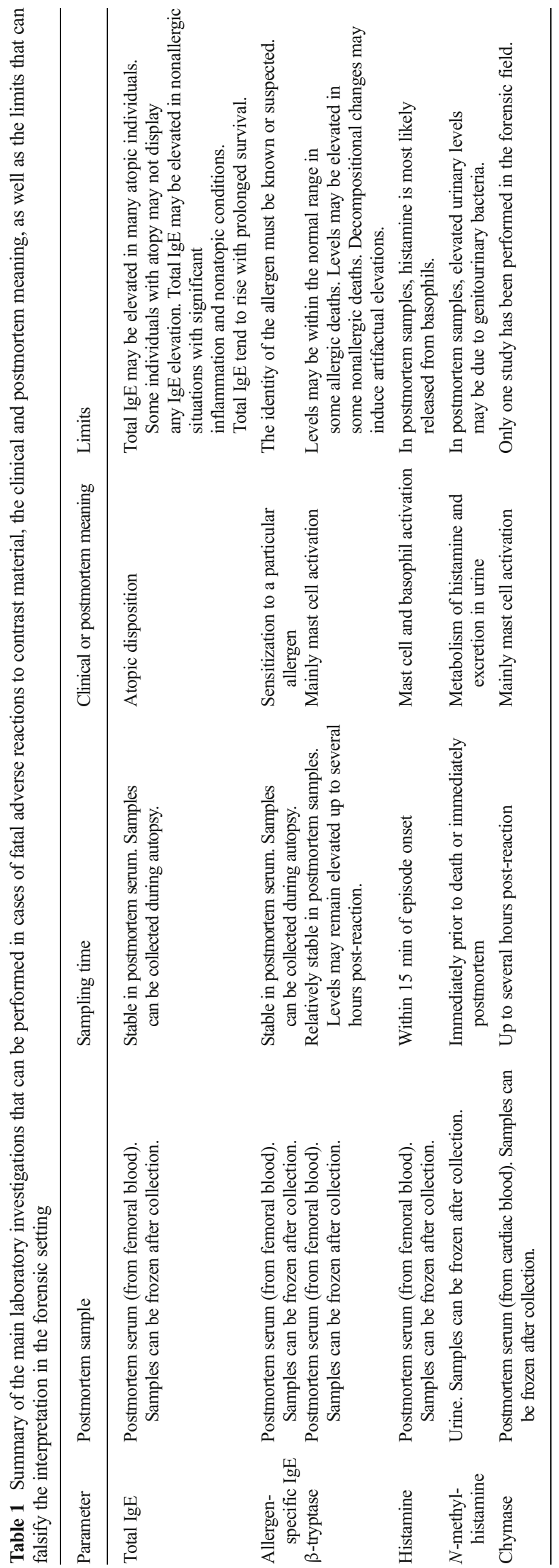


along with an IgE-independent mechanism in other individuals. Despite advanced research focusing on the pathogenesis of allergic and nonallergic reactions related to contrast media utilization, a thorough understanding of the mechanisms involved in each case continues to elude.

Mast cells and basophils are the primary effector cells of immediate hypersensitivity reactions in humans. $\beta$-tryptase is the principal protease in all mast cells, although basophils contain trace amounts. Histamine found in the plasma of living individuals can be released from either cell type whereas histamine in postmortem serum is most likely from basophils following hemolysis occurring after death. Negligible amounts of $\beta$-tryptase are stored in basophils, and markedly increased $\beta$-tryptase levels in serum and postmortem serum indicate mast cell activation. However, increased concentrations of postmortem serum $\beta$-tryptase may also be observed in situations with causes of death unrelated to allergic reactions. Total and specific IgE may be measured in postmortem serum. However, increases in total and allergen-specific IgE cannot prove death by acute hypersensitivity reactions. This leads to the conclusion that the diagnosis of fatal adverse reactions to contrast material in the forensic setting can only be formulated based on consistent, circumstantial evidence after having excluded other potential causes of death.

\section{References}

1. Schnyder B, Pichler WJ (2009) Mechanisms of drug-induced allergy. Mayo Clin Proc 84:268-272

2. Farnam K, Chang C, Teuber S, Gershwin ME (2012) Nonallergic drug hypersensitivity reactions. Int Arch Allergy Immunol 159:327345

3. Gruchalla RS (2003) Drug allergy. J Allergy Clin Immunol 111:548559

4. Solensky R, Khan DA, Bernstein IL, Bloomberg GR, Castells MC, Mendelson LM, Weiss ME, Bernstein DI, Blessing-Moore J, Cox L, Lang DM, Nicklas RA, Oppenheinmer J, Portnoy JM, Randolph C, Schuller DE, Spector S, Tilles S, Wallace D, Dowling PJ, Dykewicz M, Greenberger PA, Macy EM, May KR, Nguygen MT, Schwartz L, Solensky R, Khan DA, Bernstein IL, Bloomberg GR, Castells MC, Mendelson L, Weiss ME, Bernstein DI, Blessing-Moore J, Cox L, Lang DM, Nicklas R, Oppenheimer J, Portnoy JM, Randolph C, Schuller DE, Spector SL, Tilles SA, Wallace D, Dowling PJ, Dykewicz MS, Greenberger PA, Macy EM, May KR, Nguyen MT, Schwartz LB (2010) Drug allergy: an updated practice parameter. Ann Allergy Asthma Immunol 105:259-273

5. Edwards IR, Aronson JK (2000) Adverse drug reactions: definitions, diagnosis, and management. Lancet 356:1255-1259

6. Shah S, Shah H, Khaskheli MN, Akhtar J (2005) Adverse drug reactions: clinical assessment of drug induced disease. J Ayub Med Coll Abbottabad 17:89-91

7. Johansson SG, Hourihane JO, Bousquet J, Bruijnzeel-Koomen C, Dreborg S, Haahtela T, Kowalski ML, Mygind N, Ring J, van Cauwenberge P, van Hage-Hamsten M, Wüthrich B (2001) A revised nomenclature for allergy. An EACCI position statement from the EACCI nomenclature task force. Allergy 56:813-824
8. Johansson SG, Bieber T, Dahl R, Friedmann PS, Lanier BQ, Lockey RF, Motala C, Ortega Martell JA, Platts-Mills TA, Ring J, Thien F, Van Cauwenberge P, Williams HC (2004) Revised nomenclature for allergy for global use: report of the Nomenclature Review Committee of the World Allergy Organization, October 2003. J Allergy Clin Immunol 113:832-836

9. Vickery BP, Chin S, Burks AW (2011) Pathophysiology of food allergy. Pediatr Clin N Am 58:363-376

10. Bonds RS, Midoro-Horiuti T, Goldblum R (2008) A structural basis for food allergy: the role of cross-reactivity. Curr Opin Allergy Clin Immunol 8:82-86

11. Romano A, Guéant-Rodriguez RM, Viola M, Gaeta F, Caruso C, Guéant JL (2005) Cross-reactivity among drugs: clinical problems. Toxicology 209:169-179

12. Pichler WJ (2004) Immune mechanism of drug hypersensitivity. Immunol Allergy Clin N Am 24:373-397

13. Rajan TV (2003) The Gell-Coombs classification of hypersensitivity reactions: a re-interpretation. Trends Immunol 24:376-379

14. Galli SJ, Tsai M (2010) Mast cells in allergy and infection: versatile effector and regulatory cells in innate and adaptive immunity. Eur J Immunol 40:1843-1851

15. Riedl MA, Casillas AM (2003) Adverse drug reactions: types and treatment options. Am Fam Physician 68:1781-1790

16. Rozieres A, Vocanson M, Saï BB, Nosbaum A, Nicolas JF (2009) Role of $\mathrm{T}$ cells in nonimmediate allergic drug reactions. Curr Opin Allergy Clin Immunol 9:305-310

17. Singh J, Daftary A (2008) Iodinated contrast media and their adverse reactions. J Nucl Med Technol 36:69-74

18. Trcka J, Schmidt C, Seitz CS, Bröcker EB, Gross GE, Trautmann A (2008) Anaphylaxis to iodinated contrast material: nonallergic hypersensitivity or IgE-mediated allergy? AJR Am J Roentgenol 190:666-670

19. Geraldes CF, Laurent S (2009) Classification and basic properties of contrast agents for magnetic resonance imaging. Contrast Media Mol Imaging 4:1-23

20. Kun T, Jakubowski L (2012) Influence of MRI contrast media on histamine release from mast cells. Pol J Radiol 77:19-24

21. Böhm I, Heverhagen JT, Klose KJ (2012) Classification of acute and delayed contrast media-induced reactions: proposal of a three step system. Contrast Media Mol Imaging 7:537-541

22. Katayama H, Yamaguchi K, Kozuka T, Takashima T, Seez P, Matsuura K (1990) Adverse reactions to ionic and nonionic contrast media. A report from the Japanese Committee on the Safety of Contrast Media. Radiology 175:621-628

23. Webb JA, Stacul F, Thomsen HS, Morcos SK (2003) Late adverse reactions to intravascular iodinated contrast media. Eur Radiol 13: 181-184

24. Hoffmeister HM, Fuhrer G, Platten HP, Heller W (1989) Changes in complement components after intravascular application of contrast media. Adv Exp Med Biol 247B:585-589

25. Hoffmeister HM, Fuhrer G, Platten HP, Heller W (1987) Complement activation after the intravascular administration of contrast media: a comparison between ionic and nonionic $\mathrm{x}$-ray contrast media. Rofo 147:673-675

26. Mikkonen R, Aronen HJ, Kivisaari L, Piilonen A, Syrjäla M (1997) Plasma levels of prekallikrein, alpha-2-macroglobulin and $\mathrm{C} 1$ esterase inhibitor in patients with urticarial reaction to contrast media. Acta Radiol 38:466-473

27. Hoffmeister HM, Heller W (1996) Radiographic contrast media and the coagulation and complement systems. Invest Radiol 31:591-595

28. Brockow K (2009) Immediate and delayed reactions to radiocontrast media: is there an allergic mechanism? Immunol Allergy Clin N Am 29:453-468

29. Brockow K (2012) Immediate and delayed cutaneous reactions to radiocontrast media. Chem Immunol Allergy 97:180-190

30. Nelson KL, Gifford LM, Lauber-Huber C, Gross CA, Lasser TA (1995) Clinical safety of gadopentetate dimeglumine. Radiology 196:439-443 
31. Prince MR, Zhang H, Zou Z, Staron RB, Brill PW (2011) Incidence of immediate gadolinium contrast media reactions. AJR Am J Roentgenol 196:138-143

32. Fineschi V, Monasterolo G, Rosi R, Turillazzi E (1999) Fatal anaphylaxis shock during a fluorescein angiography. Forensic Sci Int 100:137-142

33. Su Z, Ye P, Teng Y, Zhang L, Shu X (2012) Adverse reaction in patients with drug allergy history after simultaneous intravenous fundus fluorescein angiography and indocyanine green angiography. J Ocul Pharmacol Ther 28:410-413

34. Garski TR, Staller BJ, Hepner G, Banka VS, Finney RA Jr (1978) Adverse reactions after administration of indocyanine green. JAMA 240:635

35. Iseki K, Onoyama K, Fujimi S, Omae T (1980) Shock caused by indocyanine green dye in chronic hemodialysis patients. Clin Nephrol 14:210

36. Speich R, Saesseli B, Hoffmann U, Neftel KA, Reichen J (1988) Anaphylactoid reactions after indocyanine-green administration. Ann Int Med 109:345-346

37. Benya R, Quintana J, Brundage B (1989) Adverse reactions to indocyanine green: a case report and a review of the literature. Catheter Cardiovasc Diagn 17:231-233

38. Wolf S, Arend O, Schulte K, Reim M (1992) Severe anaphylactic reaction after indocyanine green fluorescence angiography. Am J Ophthalmol 114:638-639

39. Hope-Ross M, Yannuzzi LA, Gragoudas ES, Guyer DR, Slakter JS, Sorenson JA, Krupsky S, Orlock DA, Puliafito CA (1994) Adverse reactions due to indocyanine green. Ophthalmology 101:529-533

40. Olsen TW, Lim JI, Capone A Jr, Myles RA, Gilman JP (1996) Anaphylactic shock following indocyanine green angiography. Arch Ophthalmol 114:97

41. Bézu C, Coutant C, Salengro A, Daraï E, Rouzier R, Uzan S (2011) Anaphylactic response to blue dye during sentinel lymph node biopsy. Surg Oncol 20:e55-e59

42. Barthelmes L, Goyal A, Sudheer P, Mansel RE (2010) Investigation of anaphylactic reaction after patent blue $V$ dye injection. Breast 19:516-520

43. Manson AL, Juneja R, Self R, Farquhar-Smith P, Macneill F, Seneviratne SL (2012) Anaphylaxis to Patent Blue V: a case series. Asia Pac Allergy 2:86-89

44. Howard JD, Moo V, Sivalingam P (2011) Anaphylaxis and other adverse reactions to blue dyes: a case series. Anaesth Intensive Care 39:287-292

45. Cinar H, Koca B, Kesicioglu T, Karabulut K, Karabicak I, Polat C, Tur AH (2012) Isosulfan blue-induced anaphylactic reaction during sentinel lymph node biopsy in breast cancer. Breast 21:220-222

46. Ionescu A (2009) Bubble trouble: anaphylactic shock, threatened myocardial infarction, and transient renal failure after intravenous echo contrast for left ventricular cavity opacification preceding dobutamine stress echo. Eur J Echocardiogr 10:707-710

47. Apostolou E, Deckert K, Puy R, Sandrini A, de Leon MP, Douglass JA, Rolland JM, O'hehir RE (2006) Anaphylaxis to Gelofusine confirmed by in vitro basophil activation test: a case series. Anaesthesia 61:264-268

48. Blokh I, Ganem A, Bonaros EP, Stephen BD, Steinberg B, Rosen SE (2004) Hemodynamic instability after receiving intravenous Perflutren for contrast echocardiography in an elderly female. Echocardiography 21:613-615

49. Hogan AD, Schwartz LB (1997) Markers of mast cell degranulation. Methods 13:43-52
50. Amin K (2012) The role of mast cells in allergic inflammation. Respir Med 106:9-14

51. Ogawa Y, Grant JA (2007) Mediators of anaphylaxis. Immunol Allergy Clin N Am 27:249-260

52. Lieberman P, Nicklas RA, Oppenheimer J, Kemp SF, Lang DM, Bernstein DI, Bernstein JA, Burks AW, Feldweg AM, Fink JN, Greenberger PA, Golden DB, James JM, Kemp SF, Ledford DK, Lieberman P, Sheffer AL, Bernstein DI, Blessing-Moore J, Cox L, Khan DA, Lang D, Nicklas RA, Oppenheimer J, Portnoy JM, Randolph C, Schuller DE, Spector SL, Tilles S, Wallace D (2010) The diagnosis and management of anaphylaxis practice parameter: 2010 update. J Allergy Clin Immunol 126:477-480

53. Edston E, van Hage-Hamsten M (1998) Beta-tryptase measurements post-mortem in anaphylactic deaths and in controls. Forensic Sci Int 93:135-142

54. D'Errico S, Neri M, Riezzo I, Rossi G, Pomara C, Turillazzi E, Fineschi V (2008) Beta-tryptase and quantitative mast-cell increase in a sudden infant death following hexavalent immunization. Forensic Sci Int 179:e25-e29

55. Nishio H, Suzuki K (2004) Serum tryptase levels in sudden infant death syndrome in forensic autopsy cases. Forensic Sci Int 139:57-60

56. Fineschi V, Cecchi R, Centini F, Reattelli LP, Turillazzi E (2001) Immunohistochemical quantification of pulmonary mast-cells and post-mortem blood dosages of tryptase and eosinophils cationic protein in 48 heroin-related deaths. Forensic Sci Int 120:189-194

57. Edston E, van Hage-Hamsten M (2003) Mast cell tryptase and hemolysis after trauma. Forensic Sci Int 131:8-13

58. Edston E, van Hage-Hamsten M (1995) Immunoglobulin E, mast cell-specific tryptase and the complement system in sudden death from coronary artery thrombosis. Int J Cardiol 52:77-81

59. Edston E, Eriksson O, van Hage M (2007) Mast cells tryptase in postmortem serum - reference values and confounders. Int J Legal Med 121:275-280

60. Mayer DE, Krauskopf A, Hemmer W, Moritz K, Jarisch R, Reiter C (2011) Usefulness of post mortem determination of serum tryptase, histamine and diamine oxidase in the diagnosis of fatal anaphylaxis. Forensic Sci Int 212:96-101

61. Luongo S, Frontalini C, Pesaresi M, Valsecchi M, Tagliabracci A (2011) Histopathological markers for the diagnosis of anaphylactic death. Med Sci Law 51:30-36

62. Schwartz HJ, Yunginger JW, Schwartz LB (1995) Is unrecognized anaphylaxis a cause of sudden unexpected death? Clin Exp Allergy $25: 866-870$

63. Da Broi U, Moreschi C (2011) Post-mortem diagnosis of anaphylaxis: a difficult task in forensic medicine. Forensic Sci Int 204:1-5

64. Unkrig S, Hagemeier L, Madea B (2010) Postmortem diagnostics of assumed food anaphylaxis in an unexpected death. Forensic Sci Int 198:e1-e4

65. Osawa M, Satoh F, Horiuchi H, Tian W, Kugota N, Hasegawa I (2008) Postmortem diagnosis of fatal anaphylaxis during intravenous administration of therapeutic and diagnostic agents: evaluation of clinical laboratory parameters and immunohistochemistry in three cases. Leg Med (Tokyo) 10:143-147

66. Nishio H, Takai S, Miyazaki M, Horiuchi H, Osawa M, Uemura K, Yoshida K, Mukaida M, Ueno Y, Suzuki K (2005) Usefulness of serum mast cell-specific chymase levels for postmortem diagnosis of anaphylaxis. Int $\mathrm{J}$ Legal Med 119:331-334 